\title{
PENGARUH KUALITAS PELAYANAN DAN BRAND IMAGE TERHADAP KEPUASAN PELANGGAN (STUDI KASUS HOTEL ARYADUTA LIPPO VILLAGE)
}

\author{
Suharni Rahayu \\ Emai: Dosen00964@unpam.ac.id
}

\begin{abstract}
ABSTRAK
Penelitian ini bertujuan untuk mengetahui pengaruh secara parsial kualitas pelayanan terhadap kepuasan pelanggan Hotel Aryaduta Lippo Village, Untuk mengetahui pengaruh brand image terhadap kepuasan pelanggan Hotel Aryaduta Lippo Village, Untuk mengetahui pengaruh kualitas pelayanan dan brand image secara bersama - sama terhadap kepuasan pelanggan Hotel Aryaduta Lippo Village.

Metode yang di gunakan penulis dalam penelitian ini metode deskriptif kuantitatif yaitu melakukan penelitian permasalahan yang dihadapi oleh Hotel Aryaduta Lippo Village, sedangkan pengolahan data bersifat kuantitatif dengan menggunakan software SPSS statistik. Populasi dan sampel dalam penelitian ini adalah responden yang pernah menginap di Hotel Aryaduta Lippo Village, dan penentuan jumlah sampel menggunakan metode slovin didapat 97,17 responden dan jumlah tersebut dibulatkan jumlahnya menjadi 100 orang responden, dengan cara pengambilan data menggunakan kuisioner yang diberikan kepada responden, metode pengambilan data menggunakan non Probability Sampling.

Hasil penelitian menunjukan bahwa secara parsial tidak terdapat pengaruh signifikan antara kualitas pelayanan terhadap kepuasan pelanggan Hotel Aryaduta Lippo Village, yaitu dengan Sig $>0.110>$ dari 0.05 Brand Image secara parsial berpengaruh signifikan terhadap kepuasan pelanggan, yaitu sebesar $0.041<$ dari 0.05 , dan secara bersama-sama/simultan kualitas pelayanan dan Brand Image berpengaruh terhadap kepuasan pelanggan Hotel Aryaduta Lippo Village dengan Sig sebesar 0.000 dengan uji t dan uji $\mathrm{F}$ di dapat hasil sebagai berikut: $\mathrm{t}$ hitung $>$ tabel $>0.361$ dan uji $\mathrm{F} \mathrm{r}$ hitung $>$ dari $\mathrm{r}$ tabel 0.6.
\end{abstract}

\section{Kata Kunci : Kualitas Pelayanan, Brand Image dan Kepuasan Pelanggan}

\begin{abstract}
This study aims to determine the partial effect of service quality on customer satisfaction of Aryaduta Lippo Village Hotel, To determine the effect of brand image on customer satisfaction of Aryaduta Lippo Village Hotel, To determine the effect of service quality and brand image together on customer satisfaction of Aryaduta Lippo Village Hotel.

The method used by the author in this research is quantitative descriptive method that is researching the problems faced by the Aryaduta Lippo Village Hotel, while processing quantitative data using statistical SPSS software. The population and sample in this study were respondents who had stayed at the Aryaduta Lippo Village Hotel, and the determination of the number of samples using the Slovin method was 97.17 respondents and the number was rounded to 100 respondents, by taking data using a questionnaire given to respondents, the method of taking data uses non probability sampling.

The results showed that partially there was no significant influence between service quality on customer satisfaction at Aryaduta Lippo Village Hotel, namely with
\end{abstract}


Sig> 0.110> of 0.05 Brand Image had a partially significant effect on customer satisfaction, amounting to $0.041<$ from 0.05, and together- the same / simultaneous service quality and Brand Image affect customer satisfaction Hotel Aryaduta Lippo Village with Sig of 0,000 with $t$ test and $F$ test in the results obtained as follows: $t$ count $>$ table> 0.361 and $F$ test $r$ count $>$ from $r$ table 0.6.

\section{Keywords: Service Quality, Brand Image and Customer Satisfaction}

\section{PENDAHULUAN}

\section{A. Latar Belakang Masalah}

Pelayanan adalah salah satu unsur penting dalam kegiatan usaha jasa. Di era sekarang ini dengan iklim persaingan yang semakin ketat mengharuskan setiap perusahaan melakukan beberapa strategi untuk dapat memenangkan persaingan pasar. Oleh karena itu setiap perusahaan dituntut agar mampu menciptakan produk dengan spesifikasi yang terbaik agar kepuasan pelanggan dapat terlayani. Hal tersebut menuntut kembali perusahaan agar merumuskan lagi strategi terbaik agar dapat di terima oleh pasar dengan baik. Semakin disadari bahwa pelanggan merupakan asset bagi perusahaan. Dengan pemasaran yang semakin ketat tanpa memiliki pelanggan tetap perusahaan dengan mudah mengalami risiko kemunduran dalam bisnisnya. Bahkan lebih ekstrem lagi perusahaan akan mengalami kerugian yang cukup besar dan ditinggalkan pelanggan. Mitfah (2015:97).

Kualitas pelayanan di sektor perhotelan juga merupakan unsur yang sangat penting. Pelayanan yang maksimal dan sempurna membuat tamu yang datang berkunjung merasa puas. Bentuk pelayanan itu meliputi tamu pada saat akan checkin, sampai tamu melakukan checkout. Apabila tamu merasa semua kebutuhannya terpenuhi juga merupakan bentuk pelayanan maksimal. Iklim persaingan yang ketat di dunia perhotelan dengan hadirnya hotel - hotel baru menuntut setiap manajemen hotel untuk bisa memenangkan persaingan pasar, yaitu salah satunya dengan menerapkan standar kualitas pelayanan kepada tamu secara baik. Unsur kualitas pelayanan itu ialah: bukti langsung, kehandalan, daya tanggap, jaminan dan empati.

Tujuan di terapkannya kualitas pelayanan adalah agar kita atau perusahaan memahami apa yang menjadi kehendak dari tamu. Menjadi salah satu alat ukur terhadap seluruh kegiatan perusahaan dalam melayani tamu atau sebagai rujukan bahan evaluasi sebagai pengambilan keputusan di masa yang akan datang. Dapat di artikan pula apabila ingin memenangkan persaingan pasar maka harus unggul dalam semua unsur kualitas pelayanan. Dalam hal persaingan dengan kompetitor yang sama,terlihat masih tidak stabilnya tingkat rata-rata hunian kamar pada Hotel Aryaduta Lippo Village. Pada tahun 2014 tercatat jumlah tamu yang menginap adalah 17.146 dan mengalami penurun sebesar $14,82 \%$ pada tahun 2015, menjadi hanya 14.605 pelanggan. Tahun 2015 ke 2016 masih mengalami penurunan sejumlah $12,48 \%$ dari 14.605 menjadi 12.782 , Selanjutnya pada tahun 2017 terjadi peningkatan hunian kamar menjadi 14.486 dari awalnya 12.782 (naik 13.33\%). Pada tahun 2018 kembali terjadi penurunan kembali menjadi 12.817 atau $11,52 \%$.

Dengan jumlah kamar yang ada pada saat ini di tahun 2018 yaitu sejumlah 98 kamar dari berbagai tipe, pelanggan Hotel Aryaduta Lippo Village rata-rata menginap selama dua hari, terlihat tingkat hunian pelanggan belum dapat stabil dan masih sangat variatif, ketidakstabilan tersebut dapat dipengaruhi oleh beberapa hal misalnya 
kualitas pelayanan terhadap pelanggan dan juga brand image hotel tersebut. Selain beberapa faktor tersebut pelayanan jasa yang diberikan oleh Hotel Aryaduta Lippo Village sangat mempengaruhi kepuasan pelanggan.

Selain dari faktor kualitas pelayanan dan kepuasan pelanggan dapat dilihat juga dari faktor brand image, secara sederhana brand image adalah merek atau nama yang menjadi ciri khas suatu produk atau jasa. Kepuasan pelanggan yang tercipta akan mempengaruhi brand image dari sebuah hotel yang terbentuk di benak pelanggan. Kayaman \& Arasli (2007) brand image yang kuat dapat menyebabkan peningkatan profitabilitas dan sebaliknya, lemahnya brand image pada pelayanan hotel akan mempengaruhi hilangnya aliran dana masuk yang potensial.

Fenomena yang terjadi pada saat ini, kepuasan pelanggan yang datang di Hotel Aryaduta Lippo Village tidak saja diukur dengan kualitas pelayanan dan brand image, namun juga kemudahan dalam melakukan pemesanan kamar, sarana transportasi yang mudah serta kemudahan dalam proses pembayaran. Dari pengamatan awal yang peneliti lakukan, sebagian besar pelanggan mengaku puas dengan kualitas pelayanan, namun untuk brand image masih kalah dibandingkan dengan hotel lainnya.

Berdasarkan uraian yang telah penulis uraikan tersebut, maka penulis tertarik mengambil judul penelitian sebagai berikut :"PENGARUH KUALITAS PELAYANAN DAN BRAND IMAGE TERHADAP KEPUASAN PELANGGAN HOTEL ARYADUTA LIPPO VILLAGE".

\section{B. Tujuan Penelitian}

a. Untuk mengetahui kualitas pelayanan pada Hotel Aryaduta Lippo Village. b. Untuk mengetahui brand image pada Hotel Aryaduta Lippo Village.

c. Untuk mengetahui kepuasan pelanggan pada Hotel Aryaduta Lippo Village.

d. Untuk mengetahui pengaruh kualitas pelayanan terhadap kepuasan pelanggan Hotel Aryaduta Lippo Village.

e. Untuk mengetahui pengaruh brand image terhadap kepuasan pelanggan Hotel Aryaduta Lippo Village.

f. Untuk mengetahui pengaruh kualitas pelayanan dan brand image secara bersama - sama terhadap kepuasan pelanggan Hotel Aryaduta Lippo Village.

\section{LANDASAN TEORI}

\section{A. Pengertian Pemasaran}

Pemasaran mengandung pengertian yang luas dari sekedar penjualan dan periklanan, menurut Philip Kotler dan Kevin Lane Keller (2008:6), pemasaran dapat di definisikan sebagai suatu proses sosial yang didalamnya individu dan kelompok mendapatkan apa yang mereka butuhkan serta inginkan dengan menetapkan, menawarkan dan secara bebas mempertukarkan produk yang bernilai dengan pihak lain. Maksud dari definisi diatas adalah sebuah proses sosial dimana perseorangan dan kelompok memperoleh apa yang mereka butuhkan dan inginkan melalui penciptaan, menawarkan dan mempertukarkan suatu produk yang mempunyai nilai kepada yang lain dengan mengharapkan timbal balik dan nilai dengan orang lain.

\section{B. Brand Image}

Keahlian yang sangat unik dari pemasar profesional adalah kemampuannya untuk menciptakan, memelihara, melindungi dan meningkatkan merek. Para pemasar mengatakan bahwa pemberian mereka adalah seni dan bagian paling penting 
dalam pemasaran. Brand dapat diartikan sebagai asal atau sumber dari suatu produk atau pembeda sebuah produk dari produk lainnya. Karenanya pengertian brand berbeda dengan produk. Produk meliputi benda-benda fisik, jasa layanan, toko eceran, bisnis online, orang, organisasi, tempat, maupun ide. Sedangkan brand, ada untuk sebuah produk, namun pada brand dapat ditambahkan dimensi yang menjadi pembeda dari produk-produk lain yang didesain untuk memenuhi kebutuhan yang sama Kotler, (2012:3233).

\section{Pengertian Kepuasan Pelanggan}

Kepuasan konsumen Bitner (2010:96) adalah respon atau tanggapan konsumen mengenai pemenuhan kebutuhan. Kepuasan merupakan penilaian mengenai ciri atau keistimewaan produk atau jasa, atau produk itu sendiri, yang menyediakan tingkat kesenangan konsumen berkaitan dengan pemenuhan kebutuhan konsumsi konsumen.

\section{METODOLOGI PENELITIAN}

\section{A. Ruang Lingkup Penelitian}

\section{Tempat Penelitian}

Tempat penelitian ini dilaksanakan di Hotel Aryaduta Lippo Village yang beralamat di jalan 401 Boulevard Jenderal Sudirman Lippo Village 1300, Tangerang, Banten, 15811.

\section{Waktu Penelitian}

Periode pengambilan data dan penelitian yaitu pada bulan Oktober 2018 sampai dengan Desember 2018.

\section{B. Metode Penentuan Sampel}

\section{Populasi}

Populasi dalam penelitian ini adalah jumlah rata-rata pelanggan yang menginap dari bulan september hingga desember yaitu sejumlah 3429 responden.

2. Sampel

$$
\begin{aligned}
\mathrm{n} & =\frac{3429}{1+\left(3429(0.01)^{2}\right)} \\
& =\frac{3429}{1+34.29} \\
& =\frac{3429}{35.29=97,17}
\end{aligned}
$$

Dalam hasil perhitungan ini menggunakan metode slovin, terhitung jumlah responden sebanyak 97.17 pelanggan, sedangkan e ditetapkan 10\% dimana hasil tersebut dibulatkan menjadi 100 responden. Menurut roscoe dalam penelitian setyo fery wibowo yang mengatakan bahwa ukuran sampel yang layak dalam penelitian ini adalah antara 30 sampai 500. Oleh karena itu peneliti memilih sampel sebanyak 100 responden.

\section{E. Metode Analisa data}

\section{Uji Regresi Linier Berganda}

$\mathrm{Y}=\mathrm{a}+\mathrm{b}_{1} \mathrm{X}_{1}+\mathrm{b}_{2} \mathrm{X}_{2}+\mathrm{b}_{3} \mathrm{X}_{3}+\mathrm{e}$

Keterangan :

Y : Kepuasan Konsumen

a : Konstanta

$b_{1}, b_{2}, b_{3}$ : Koefisien Regresi

$\mathrm{X}_{1}$ : Variabel kualitas pelayanan

$\mathrm{X}_{2}$ : Variabel harga

$\mathrm{X}_{3}$ : Variabel brand image

e : Standar Eror

\section{Uji Hipotesis}

Hipotesis merupakan jawaban atau dugaan sementara yang harus di uji kebenarannya, Syofian Siregar (2014:65). Hipotesis harus mengekspresikan suatu fenomena (satu variabel) atau mengekspresikan suatu hubungan/pengaruh antara dua variabel atau lebih. Sedangkan Menurut Arikunto (2010:55) mengemukakan bahwa hipotesis adalah alternatif dugaan 
jawaban yang dibuat oleh peneliti bagi problematika yang diajukan dalam penelitiannya.

Untuk menguji hipotesis, dapat menggunakan rumus berikut ini :

\section{HASIL PENELITIAN DAN PEMBAHASAN}

\section{A. Uji Korelasi Product Moment Hasil Uji Koefisien Korelasi Product Moment}

\begin{tabular}{|l|l|l|l|l|}
\hline $\begin{array}{l}\text { Mod } \\
\text { el }\end{array}$ & $R$ & $\begin{array}{l}\text { R } \\
\text { Squa } \\
\text { re }\end{array}$ & $\begin{array}{l}\text { Adjust } \\
\text { ed R } \\
\text { Squar } \\
\text { e }\end{array}$ & $\begin{array}{l}\text { Std. } \\
\text { Error } \\
\text { of the } \\
\text { Estim } \\
\text { ate }\end{array}$ \\
\hline 1 & $\begin{array}{l}.21 \\
9^{a}\end{array}$ & .048 & .028 & $\begin{array}{l}2.244 \\
66\end{array}$ \\
\hline
\end{tabular}

a. Predictors: (Constant), Kualitas Pelayanan, Brand Image

b. Dependent Variable: Kepuasan Pelanggan

Nilai koefisien korelasi dapat dilihat dengan nilai $\mathrm{R}$ yaitu 0,219 dimana kualitas pelayanan (x1) dan Brand Image (x2) memiliki hubungan yang rendah terhadap kepuasan pelanggan $(\mathrm{y})$ karena 0,219 berada diantara $(0,20 \mathrm{~s} / \mathrm{d}$ 0,39 : kuat)

\section{B. Uji Koefisien Determinasi Koefisien Determinasi}

\begin{tabular}{|l|l|l|l|l|}
\hline $\begin{array}{l}\text { Mod } \\
\text { el }\end{array}$ & $R$ & $\begin{array}{l}\text { R } \\
\text { Squa } \\
\text { re }\end{array}$ & $\begin{array}{l}\text { Adjust } \\
\text { ed R } \\
\text { Squar } \\
\text { e }\end{array}$ & $\begin{array}{l}\text { Std. } \\
\text { Error } \\
\text { of the } \\
\text { Estim } \\
\text { ate }\end{array}$ \\
\hline 1 & $\begin{array}{l}.21 \\
9^{a}\end{array}$ & .048 & .028 & $\begin{array}{l}2.244 \\
66\end{array}$ \\
\hline
\end{tabular}

a. Predictors: (Constant), Kualitas Pelayanan, Brand Image

b. Dependent Variable: Kepuasan Pelanggan

Hasil dari perhitungan regresi dapat diketahui bahwa dari koefisien determinasi $\mathrm{R}^{2}$ diperoleh sebesar 0,048. Hal ini berarti $48 \%$ Kepuasan
Pelanggan dapat dipengaruhi oleh Kualitas pelayanan, Brand Image, sedangkan $100-48=52 \%$ sisanya dapat dipengaruhi oleh variabel lain yang tidak diteliti dalam model regresi ini.

C. Pengujian Hipotesis

1. Uji Parsial (t)

\section{Uji Parsial (t)}

\begin{tabular}{|c|c|c|c|c|c|c|}
\hline \multirow{2}{*}{\multicolumn{2}{|c|}{ Model }} & \multicolumn{2}{|c|}{$\begin{array}{l}\text { Unstand } \\
\text { ardized } \\
\text { Coeffici } \\
\text { ents }\end{array}$} & \multirow{2}{*}{$\begin{array}{l}\text { Stand } \\
\text { ardize } \\
\text { d } \\
\text { Coeffi } \\
\text { cients } \\
\text { Beta }\end{array}$} & \multirow{2}{*}{$\mathrm{t}$} & \multirow{2}{*}{$\begin{array}{l}\mathrm{Si} \\
\text { g. }\end{array}$} \\
\hline & & B & $\begin{array}{l}\text { St } \\
\text { d. } \\
\text { Err } \\
\text { or }\end{array}$ & & & \\
\hline 1 & $\begin{array}{l}\text { (Con } \\
\text { stant } \\
\text { ) }\end{array}$ & $\begin{array}{l}21 . \\
64 \\
5\end{array}$ & $\begin{array}{l}2 . \\
31 \\
9\end{array}$ & & $\begin{array}{l}9 . \\
33 \\
5\end{array}$ & $\begin{array}{l}.0 \\
0 \\
0\end{array}$ \\
\hline & $\begin{array}{l}\text { Kuali } \\
\text { tas } \\
\text { Pela } \\
\text { yana } \\
n\end{array}$ & $\begin{array}{l}.25 \\
9\end{array}$ & $\begin{array}{l}.1 \\
61\end{array}$ & .418 & $\begin{array}{l}1 . \\
61 \\
2\end{array}$ & $\begin{array}{l}.1 \\
1 \\
0\end{array}$ \\
\hline & $\begin{array}{l}\text { Bran } \\
\text { d } \\
\text { Imag } \\
\text { e }\end{array}$ & $\begin{array}{l}.48 \\
4\end{array}$ & $\begin{array}{l}.2 \\
34\end{array}$ & -.536 & $\begin{array}{l}- \\
2 . \\
06 \\
8\end{array}$ & $\begin{array}{l}.0 \\
4 \\
1\end{array}$ \\
\hline
\end{tabular}

a. Dependent Variable: Kepuasan Pelanggan

a. Hasil dari pengujian diperoleh nilai t hitung untuk variabel Kualitas Pelayanan terhadap Kepuasan Pelanggan menunjukkan bahwa nilai $\mathrm{t}$ hitung $=1.612$, dengan signifikasi $0,110 . \quad$ dengan menggunakan batas signifikansi sebesar 0,05 , nilai signifikansi lebih besar dari 0,05. Dengan arah koefisiennya adalah negatif, maka dengan demikian dapat diperoleh bahwa hipotesis menyatakan Kualitas Pelayanan tidak memiliki pengaruh terhadap kepuasan pelanggan, Artinya H1 diterima.

b. Dari hasil pengujian diperoleh nilai t hitungnya untuk variabel Brand Image terhadap Kepuasan 
Pelanggan menunjukkan bahwa nilai $\mathrm{t}$ hitung $=2.068$ dengan signifikasi 0,041 dengan menggunakan batas signifikansi sebesar 0,05 , nilai signifikansi < dari 0,05. Dengan arah koefisiennya adalah positif, dengan demikian diperoleh bahwa Brand Image memiliki pengaruh terhadap Kepuasan Pelanggan dapat diterima, Artinya hipotesis 2 diterima

\section{Uji Simultan (F)}

\section{Uji Simultan F}

ANOVA $^{\mathrm{a}}$

\begin{tabular}{|c|c|c|c|c|c|c|}
\hline \multicolumn{2}{|c|}{ Model } & $\begin{array}{l}\text { Sum } \\
\text { of } \\
\text { Squ } \\
\text { ares }\end{array}$ & $\begin{array}{l}d \\
f\end{array}$ & $\begin{array}{l}\text { Me } \\
\text { an } \\
\text { Squ } \\
\text { are }\end{array}$ & $F$ & $\begin{array}{l}\text { Si } \\
\text { g. }\end{array}$ \\
\hline \multirow[t]{3}{*}{1} & $\begin{array}{l}\text { Regre } \\
\text { ssion }\end{array}$ & $\begin{array}{l}24.6 \\
54\end{array}$ & 2 & $\begin{array}{l}12 . \\
327\end{array}$ & $\begin{array}{l}2.4 \\
47\end{array}$ & $\begin{array}{l}.0 \\
92 \\
b\end{array}$ \\
\hline & $\begin{array}{l}\text { Resid } \\
\text { ual }\end{array}$ & $\begin{array}{l}488 . \\
736 \\
\end{array}$ & $\begin{array}{l}9 \\
7 \\
\end{array}$ & $\begin{array}{l}5.0 \\
39 \\
\end{array}$ & & \\
\hline & Total & $\begin{array}{l}513 . \\
390\end{array}$ & $\begin{array}{l}9 \\
9\end{array}$ & & & \\
\hline
\end{tabular}

a. Dependent Variable: Kepuasan pelanggan

b. Predictors: (Constant), Kualitas Pelayanan Brand Image

Hasil pengujian dapat diperoleh nilai $\mathrm{F}$ hitung sebesar 2.447 Dengan signifikansi 0,092 Dengan menggunakan batas signifikasi 0,05 nilai signifikansi tersebut < dari 0,05 . Dengan demikian diperoleh bahwa hipotesis Kualitas Pelayanan dan Brand Image secara bersama-sama memiliki pengaruh terhadap kepuasan pelanggan Hotel Aryaduta Lippo Village.

\section{KESIMPULAN DAN SARAN}

\section{A. Kesimpulan}

1. Berdasarkan keseluruhan indikator Kualitas Pelayanan dikatakan Tinggi, hal ini dapat dilihat dari total jawaban yang memiliki kategori skala tinggi atau baik, dengan skor tertinggi adalah 4,27 pada indikator bukti langsung dimana pernyataan "Hotel Aryaduta Lippo Village memiliki fasilitas lengkap seperti kolam renang, fitness, convention dan Spa serta outlet food".

2. Berdasarkan keseluruhan indikator Brand Image dikatakan Tinggi, hal ini dapat dilihat dari total jawaban yang memiliki kategori skala tinggi atau baik, dengan skor tertinggi adalah 4,31 pada indikator ciri khas dimana pernyataan "Desain yang di gunakan Hotel Aryaduta Lippo Village memiliki ciri khas tertentu". Hal ini membuktikan bahwa banyak pelanggan yang tertarik dengan Hotel Aryaduta Lippo Village dari tampilannya.

3. Berdasarkan keseluruhan indikator Kepuasan Pelanggan dikatakan Tinggi, hal ini dapat dilihat dari total jawaban yang memiliki kategori skala tinggi atau baik, dengan skor tertinggi adalah 3,97 pada indikator kondisi lingkungan dimana pernyataan "Saya merasa nyaman saat berada di kamar Hotel Aryaduta Lippo Village". Hal ini membuktikan bahwa banyak pelanggan yang merasa nyaman dan tenang saat berada di kamar Hotel Aryaduta Lippo Village.

4. Berdasarkan rumusan masalah maka Kualitas Pelayanan tidak memiliki pengaruh yang positif dan signifikan terhadap 
Kepuasan Pelanggan dimana diperoleh nilai $\mathrm{t}$ hitung < $\mathrm{t}$ tabel $(1,612<$ 1,980) dan sig >0,05 $(0,110$ $>0,05)$.

5. Berdasarkan rumusan masalah maka Brand Image memiliki pengaruh yang positif dan signifikan terhadap kepuasan pelanggan dimana diperoleh nilai $\mathrm{t}$ hitung $<\mathrm{t}$ tabel ($2,068<1,980)$ dan sig < $0,05(0,041<0,05)$.

6. Berdasarkan rumusan masalah maka Kualitas Pelayanan dan Brand Image secara bersama - sama memiliki pengaruh yang positif dan signifikan terhadap Kepuasan Pelanggan dimana diperoleh nilai $\mathrm{F}$ hitung $<\mathrm{F}$ table yaitu $2,447<3,09$ dan nilai sig < 0,05 atau $0,092>0,05$.

B. Saran

1. Perusahaan harus meningkatkan kembali kualitas pelayanan dari indikator keandalan yaitu pegawai hotel aryaduta lippo village memberi pelayanan dengan maksimal

2. Perusahaan harus meningkatkan kembali kualitas pelayanan dari indikator daya tanggap yaitu karyawan hotel aryaduta lippo village memberikan informasi yang dibutuhkan pelanggan secara tepat

3. Perusahaan harus meningkatkan kembali brand image dari indikator citra positif yaitu Hotel Aryaduta Lippo Village sudah dikenal oleh beberapa kalangan sosial

4. Perusahaan harus meningkatkan kembali brand image dari indikator dikenal luas yaitu Identitas perusahaan dapat diperoleh langsung oleh setiap pelanggan yang berkunjung atau melalui website

5. Perusahaan harus meningkatkan kembali kepuasan pelanggan dari indicator kulaitas produk, yaitu saya merasa puas dengan fasilitas yang di berikan Hotel Aryaduta Lippo Village

6. Perusahaan harus meningkatkan kembali kepuasan pelanggan dari indicator karyawan dan staff, yaitu saya merasa puas dengan pelayanan yang cepat dalam menanggapi keluhan

\section{DAFTAR PUSTAKA}

Almasdi, dan Jusuf Suit. 2012. Aspek Sikap Mental Dalam Manajemen Sumber. Daya Manusia. Jakarta: Syiar Media

Anissa Fatia Noor dan Lupiyoudi Rambat. 2013. Analisis Pengaruh Kualitas Pelayanan terhadap Kepuasan Pelanggan, Loyalitas Pelanggan dan Citra Merek Hotel Berbasis Syariah: Studi Kasus Hotel Sofyan. Jurnal Ekonomi Fakultas Manajemen Universitas Indonesia.

Arikunto, Suharsimi. 2007. Prosedur Penelitian Suatu Pendekatan Praktik. Rineka Cipta, Jakarta.

Bilson. 2013. Riset Pemasaran. Jakarta : PT. Gramedia Pustaka Utama P. Siagian,

Bitner, M. J. dan Zeithaml, V. A., 2010, Service Marketing (3 rd ed.), Tata. McGraw Hill, New Delhi. 
Buchari Alma. 2013, Manajemen Pemasaran \& Pemasaran Jasa. Bandung: CV. Alfabeta.

Caroline Olive dan Kuswoyo Chandra. 2013. Pengaruh Kualitas Pelayanan dan Harga Terhadap Loyalitas Pelanggan Melalui Kepuasan Pelanggan Hotel Zodiak Kota Bandung. Jurnal Manajemen, Vol.12, No.2, Mei 2013

Charles W. Lamb, Joseph F. Hair, CarlMcdaniel. 2011. Pemasaran. Edisi. Pertama, Salemba Empat, Jakarta

Chen, et al. 2007. An empirical investigation of the relationship between intellectual capital and firm's market value and financial performance. Journal of Intellectual Capital, Vol 6, Issue 2.

Djaslim Saladin, 2007, Manajemen Pemasaran, Bandung: Linda Karya Donnelly Durianto, Sugiarto,

Frizawati. M. 2012. Pengantar Perbankan. Palembang: Penerbit. CitraBooks.

Garvin, David, "Managing Quality". 2012. Manajemen Alutu Terpadu (Fotal Quality Management).Jakarta: Ghalia Indonesia

Hariyanto David dan Subagio Hartono. 2013. Analisis Pengaruh Kualitas Layanan, Brand Image dan Atsmosfir Terhadap Loyalitas Konsumen Dengan Kepuasan Konsumen Sebagai Variabel Intervening Konsumen Kedai Dejavu Surabaya. Jurnal
Manajemen Pemasaran Vol 1 No. 1 Tahun 2013.

Hariyanto Dedi dan Untarini Nindria.2014. Pengaruh Kualitas Pelayanan Terhadap Kepuasan Pelanggan Hotel JW Marriot Surabaya. Jurnal Ilmu Manajemen.Volume 2 Nomor 4 Oktober 2014

Katz, Daniel \& Kahn, Robert L. 2011. The Social Psychology of Organizations.New York. Elsevi

Kotler, Philip and Gary Armstrong. 2012. Prinsip-prinsipPemasaran. Edisi. 13. Jilid 1. Jakarta: Erlangga

Lumantoro Hengky. 2015. Pengaruh Citra Hotel Terhadap Loyalitas Pelanggan: Penguji Kepuasan Pelanggan Sebagai Variabel Mediasi. Jurnal Ekonomi.Fakultas Ekonomi Universitas Atma Jaya Yogyakarta

Lupiyoadi, Hamdani. 2013. Manajemen Pemasaran Jasa, Edisi Kedua. Jakarta : Penerbit Salemba Empat

Miftah Thoha. 2015, Kepemimpinan Dalam Manajemen. Jakarta : PT. Raja Grafindo Persada.

Pasaribu, V. L. D., \& Jaenanto, J. (2020, January). PENGARUH KUALITAS PELAYANAN TERHADAP TINGKAT KEPUASAN PENYEWA RUANG KANTOR DI PT ISMAWA TRIMITRA GEDUNG GRAHA ISKANDARSYAH PERIODE 2018 JAKARTA SELATAN. In PROCEEDINGS (Vol. 1, No. 1).

PASARIBU, V. L. D. (2017). 


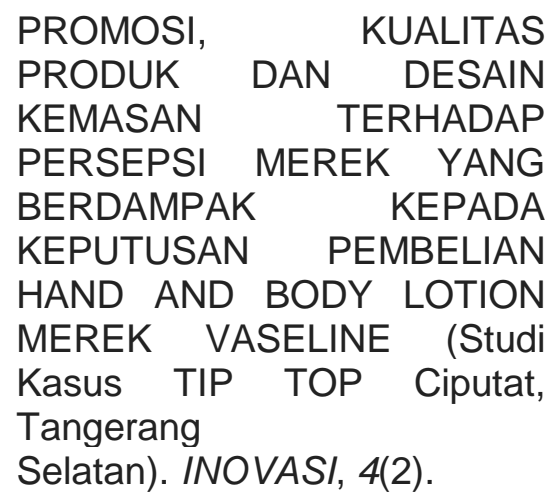

Qurbani, D., \& Pasaribu, V. L. D. (2019). PENGARUH BRAND IMAGE DAN BRAND TRUST TERHADAP BRAND LOYALTY NASABAH PRUDENTIAL SYARIAH PADA PT. FUTURISTIK ARTHA GEMILANG (Studi kasus di kantor cabang agensi Prudential Syariah PT. Futuristik Artha Gemilang Jakarta Selatan). Jurnal Pemasaran Kompetitif, 2(3), 121-135.

Rifky Aditya, Rodiyah dan Saryadi. 2015. Pengaruh Tarif Kamar dan Kualitas Pelayanan Terhadap Loyalitas Pelanggan Melalui Kepuasan Pelanggan Pada Hotel Horison Semarang. Diponegoro Jurnal Of Social dan Politic.

Sekaran, Uma. 2011. Metodologi Penelitian untuk Bisnis. Jilid 2. Edisi 4., jakarta : Salemba Empat.

Setyowati Erni, 2015. Pengaruh Kualitas Pelayanan, Harga, dan Citra Merek Terhadap Loyalitas Pelanggan dengan Kepuasan Pelanggan Sebagai Variabel Mediasi. Jurnal Pascasarjana Magister Manajemen. Universitas Muhammadiyah Surakarta.

Sondang.2014. Kepemimpinan Organisasi \& Perilaku
Administrasi,. Jakarta: Penerbit Gunung Agung

Sugiono. 2010. Metode Penelitian Kuantitatif, kualitatif dan $R \& D$. Bandung: Alfabeta.

Suryadharma I Wayan Widia dan Nurcahya I Ketut. 2015. Pengaruh Kepuasan Pelayanan terhadap Kepuasan Pelanggan Hotel Bintang Pesona di Denpasar Timur. E-Jurnal Manajemen Unud, Vol. 4, No. 4, 2015: 930-942 ISSN : 2302-8912

Sutedja, Wira. 2007. Panduan Layanan Konsumen. Jakarta: PT. Grasindo

Tjiptono, Fandy. 2015. Strategi Pemasaran. Edisi Kedua. Cetakan Kelima. Yogyakarta : Andi Offset 